\section{Poly (ADP-ribose) polymerase 1 protein expression in normal and neoplastic prostatic tissue}

\author{
M. Salemi, ${ }^{1}$ A. Galia, ${ }^{2}$ F. Fraggetta, ${ }^{2}$ \\ C. La Corte, ${ }^{2}$ P. Pepe, ${ }^{3}$ S. La Vignera, ${ }^{1}$ \\ G. Improta, ${ }^{4}$ P. Bosco, ${ }^{5}$ A.E. Calogero1
}

'Section of Endocrinology, Andrology and Internal Medicine, Department of Medical and Pediatric Sciences, University of

Catania, Italy; ${ }^{2}$ Pathology Unit,

Cannizzaro Hospital, Catania, Italy; 3Urology Unit, Cannizzaro Hospital, Catania, Italy; ${ }^{4}$ Laboratory of Clinical Research and Molecular Diagnostics, IRCCS-CROB Hospital, Rionero in Vulture, PT, Italy; ${ }^{5}$ Laboratory of Cytogenetics, Oasi Institute for Research on Mental Retardation and Brain Aging, Troina, EN, Italy

\section{Abstract}

A genetic background has been implicated in the development of prostate cancer. Protein microarrays have enabled the identification of proteins, some of which associated with apoptosis, that may play a role in the development of such a tumor. Inhibition of apoptosis is a cofactor that contributes to the onset and progression of prostate cancer, though the molecular mechanisms are not entirely understood. Poly (ADP-ribose) polymerase 1 (PARP-1) gene is required for translocation of the apoptosis-inducing factor (AIF) from the mitochondria to the nucleus. Hence, it is involved in programmed cell death. Different PARP-1 gene expression has been observed in various tumors such as glioblastoma, lung, ovarian, endometrial, and skin cancers. We evaluated the expression of PARP-1 protein in prostatic cancer and normal prostate tissues by immunohistochemistry in 40 men with prostate cancer and in 37 normal men. Positive nuclear PARP-1 staining was found in all samples (normal prostate and prostate cancer tissues). No cytoplasmic staining was observed in any sample. PARP-1-positive cells resulted significantly higher in patients with prostate carcinoma compared with controls $(\mathrm{P}<0.001)$. PARP-1 over-expression in prostate cancer tissue compared with normal prostate suggests a greater activity of PARP-1 in these tumors. These findings suggest that PARP-1 expression in prostate cancer is an attempt to trigger apoptosis in this type of tumor similarly to what reported in other cancers.

\section{Introduction}

Prostate cancer $(\mathrm{PCa})$ is one of the most commonly diagnosed male malignancies; some of them are slow growing, whereas others are more aggressive. ${ }^{1}$ Many factors, including genetics, have been implicated in the development of Pca. ${ }^{2}$ Men who have a brother or father with PCa have twice the risk of developing Pca. ${ }^{3,4}$ Cancer cells may metastasize from the prostate to other parts of the body, particularly the bones and lymph nodes. Moreover, there is a significant number of men who require systemic therapy and ongoing surveillance for advanced Pca. ${ }^{5}$ Therefore, genetic studies of this disease and new therapeutic strategies are urgently needed for the prevention and the treatment of PCa.

Apoptosis is a programmed cell death process that takes place under normal physiological and pathological conditions. Inhibition of apoptosis is a critical pathophysiological factor that contributes to the onset and progression of $\mathrm{PCa}$, but the molecular mechanisms are not entirely understood. Therefore, insight into the mechanism(s) of an abnormal apoptosis regulation may be the basis for developing more effective therapeutic approaches to destroy apoptosis-resistant tumor cells, as those found in Pca. ${ }^{6,7}$

Poly (ADP-ribose) polymerase 1 (PARP-1) gene is located to 1q42; it is $43 \mathrm{~kb}$ long and is split into 23 exons (OMIM 173870). PARP-1 is a chromatin associated enzyme that participates to cell cycle regulation, transcription, tumorigenesis, and cellular response to DNA damage. ${ }^{8-10}$ PARP-1 has an important roles in DNA base excision repair (BER), acting as a nick sensor, and modulator of key DNA repair molecules. ${ }^{11}$ Upon activation, PARP-1 synthesizes poly (ADP-ribose) (PAR) using nicotinamide adenine dinucleotide (NAD+) as a substrate and covalently transfers PAR to nuclear proteins, including nucleosomal core histones, topoisomerases I and II, high mobility group (HMG) proteins, and p53. ${ }^{12}$ Genetic and pharmacological studies have shown that PARP-1 overexpression is a key mediator of programmed-necrotic cell death in vivo. Furthermore, PARP1 is required for translocation of the apoptosis-inducing factor (AIF) from the mitochondria to the nucleus ${ }^{13}$ and it is proteolytically cleaved at the onset of apoptosis by CASP3. ${ }^{13}$ PARP-1 appears to be also involved in programmed cell death processes, such as apoptosis or macroautophagocytotic cell death. ${ }^{13}$ Analysis of PARP-1 gene expression showed that PARP-1 is highly expressed in several types of tumors including prostate cancer, colorectal cancer, pancreatic cancer, hepatocellular carcinoma, cutaneous malignant melanomas, and glioblastoma multi-
Correspondence: Dr. Michele Salemi, Section of Endocrinology, Andrology and Internal Medicine, Department of Medical and Pediatric Sciences, University of Catania, via S. Sofia 78, 95123 Catania, Italy.

E-mail: micezia@tiscali.it

Key words: prostate cancer, $P A R P-1$ gene; protein expression; immunoistochemistry.

Received for publication: 13 December 2012. Accepted for publication: 4 February 2013.

This work is licensed under a Creative Commons Attribution NonCommercial 3.0 License (CC BYNC 3.0).

CC Copyright M. Salemi et al., 2013

Licensee PAGEPress, Italy

European Journal of Histochemistry 2013; 57:e13 doi:10.4081/ejh.2013.e13

forme. ${ }^{13-19}$. The present study was undertaken to evaluate the expression of PARP-1 protein by immunohistochemistry in normal prostate tissues and in prostate cancer according to their Gleason score. The Gleason score system, in addition to other parameters, is used to evaluate the prognosis of men with prostate cancer and to guide the treatment. A Gleason score is given to prostate cancer based upon its microscopic appearance. ${ }^{20}$ Cancers with higher Gleason score are more aggressive and have a worse prognosis.

\section{Materials and Methods}

\section{Patient and control prostate samples}

The study included 40 cases of PCa with different Gleason score, and 37 cases of normal prostatic tissues (6 prostates removed by post mortem autopsy in normal donors and 31 prostatic biopsies). The diagnosis and grading of PCa was made according to the 2005 International Society of Urological Pathology (ISUP) Consensus Conference, ${ }^{21}$ by two different pathologists (AG and FF). The protocol was approved by the internal Institutional Review Board and an informed written consent was obtained from each patient with PCa or, if deceased, by his/her relatives.

\section{Immunohistochemical staining}

Prostate section (4 m thick) were obtained from all normal donors and PCa patients. All sections were formalin-fixed and paraffinembedded following standard methods.

PARP-(F-2), a mouse monoclonal antibody raised against human PARP-1 protein, was used for immunohistochemistry (Santa Cruz 
Biotechnology, Inc., Heidelberg, Germany). As indicated by the manufacturer instructions, this antibody, at the dilution of 1:300, has been shown to reliably recognize PARP-1 proteins in $\mathrm{PCa}$ and normal prostate by immunohistochemistry. Slides were deparaffinized, rehydrated, subjected to three 5 min cycles in a microwave at $360 \mathrm{~W}$ in citrate buffer, preincubated in $3 \% \mathrm{H}_{2} \mathrm{O}_{2}$ in citrate buffer, and thoroughly washed in $50 \mathrm{~mm}$ Tris-Cl (pH 7.4), 150 $\mathrm{mm} \mathrm{NaCl}$ Tris buffered saline (TBS) containing $0.05 \%$ Tween 20 (washing buffer). Slides were then pre-incubated with $3 \%$ bovine serum albumin (BSA) in TBS for $30 \mathrm{~min}$, incubated with 1:300 dilution of anti-PARP-1 antibody in TBS containing 1\% BSA, thoroughly washed in washing buffer before detection with the LSAB 2 kit (anti mouse, biotinylated and peroxidase-labeled streptavidin) and 3,3diaminobenzidine-4HCl (DAB; Dako, Carpinteria, CA, USA) following the instructions contained in the kit. After detection, the sections were counterstained with haematoxylin, dehydrated and mounted in xylenbased DPX mountant (BDH, Pool, UK). ${ }^{22}$

\section{Microscopic evaluation}

Slides were observed and cells visually scored at 10x, 20x, and 40x. To evaluate the percentage of positive tumor cells, at least 500 cells were analyzed for each prostate cancer and normal prostate tissue. PARP-1 positive cells were evaluated independently in a blinded fashion by two observers (GA and SM). No significant difference was observed between the two observers.

\section{Statistical analysis}

Results are reported as mean \pm SEM. Data were analyzed by Student's $t$-test or 1-way analysis of variance (ANOVA) followed by the Duncan's Multiple Range test. The statistical significance was accepted when the $\mathrm{p}$ value was lower than 0.05 .

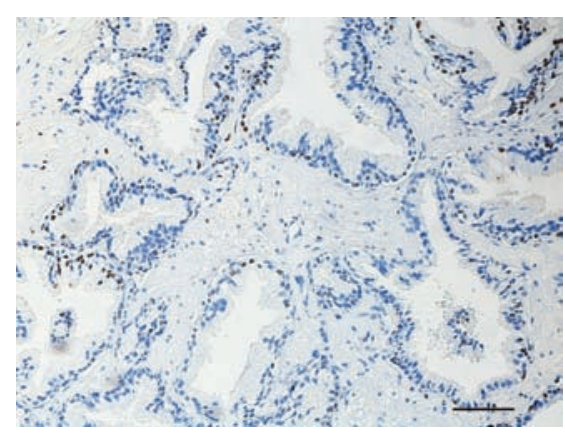

Figure 1. Immunohistochemistry of normal prostate. Hematoxylin counterstain; scale bar: $80 \mathrm{~m} \mu$.

\section{Results}

Patients with prostate carcinoma had a mean of $69.3 \pm 8.0$ years, which did not differ significantly from controls $(73.0 \pm 9.0$ years). Immunohistochemical analysis of paraffinembedded sections revealed a strong nuclear signals for PARP-1 staining in both normal and prostate carcinoma cells. No cytoplasmic staining was observed in any sample of both groups (Figure 1; Figure 2A,B). The percentage of PARP-1-positive cells resulted significantly higher in patients with prostate carcinoma compared with controls $(\mathrm{P}<0.001$, Student's $t$ test) (Figure 3). According to the Gleason score, the percentage of cells with positive nuclear PARP-1 staining resulted significantly higher than controls compared to that observed in patients with Gleason scores of 6 (9 cases), 7 (10 cases), 8 (16 cases) or 9 (5 cases) $(\mathrm{P}<0.05$, ANOVA followed by Duncan test) (Figure 4). In addition, the percentage of PARP-1-positive nuclei in patients with a Gleason score of 8 were significantly higher than that observed in patients with a Gleason score of $6(\mathrm{P}<0.05$, ANOVA followed by Duncan test) (Figure 4).
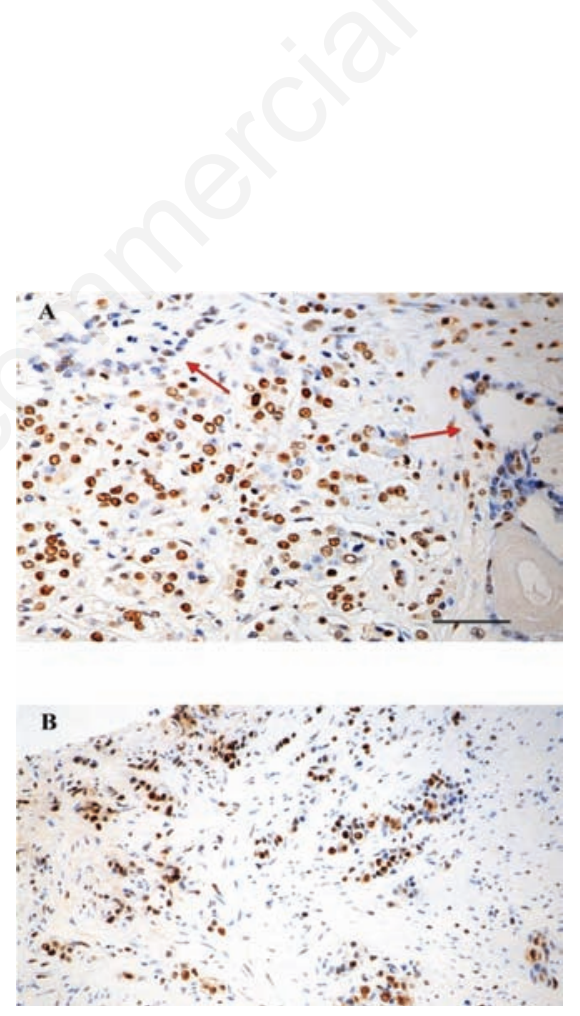

Figure 2. Immunohistochemistry of prostate cancer and normal prostate. A) Prostate cancer Gleason score 8, the red arrows indicate tubules of normal prostate; hematoxylin counterstain; Scale bar: 200 $\mathrm{m} \mu$. B) Prostate cancer Gleason score 9; hematoxylin counterstain; scale bar: $80 \mathrm{~m} \mu$.

\section{Discussion}

A significantly higher number in cells expressing PARP-1 proteins in PCa tissues compared with the normal prostate cells confirmed previous studies showing the association of this gene over-expression with tumors. ${ }^{4}$ Also, Ossovskaya et al. (2010) had already shown a higher PARP-1 mRNA expression in prostate cancer. ${ }^{13}$ The greater expression of PARP-1 protein in PCa compared to normal prostate may relate to the its close functional/structural relationship with the factors which favors the activation of the proapoptotic mechanisms, suggesting that proapoptotic mechanisms may be activated in these tumors.

PARP-1 gene plays a important role in apoptosis. This may, in part, justify the presence of PARP-1 protein in some tumors, such as nonHodgkin's lymphomas, breast, ovarian, lung, endometrial and skin cancers. ${ }^{14}$ PARP-1 is an abundant, chromatin-associated enzyme present in all eukaryotic cell nuclei, where it plays an important function in the maintenance of genomic integrity and transcriptional control. $^{14,23}$ Poly(ADP-ribose) polymerase-1

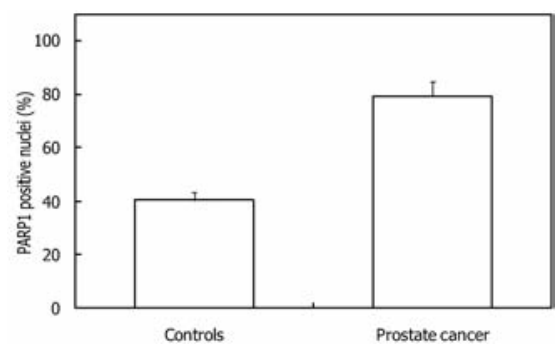

Figure 3. Percentage of PARP-1-positive nuclear signals in cells of prostate cancer and normal prostate (controls).

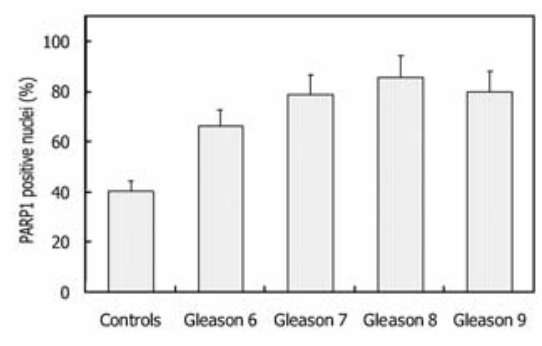

Figure 4. Percentage of PARP-1-positive nuclear signals in cells of prostate cancer (according to Gleason score) and normal prostate (controls). 
inhibitor, increases the antitumor activity against glioma, intracranial melanoma, lymphoma, and hematological neoplasias. ${ }^{24-27}$ These observations suggest a potential role of PARP-1 inhibitors in the treatment of $\mathrm{PCa}$. Activation of PARP-1 gene in response to DNA damage is an important mechanism to maintain the homeostasis or to trigger apoptosis. The function of PARP-1 has been studied in primary human lung cell cultures from normal human bronchial epithelial cells (NHBEC) and peripheral lung cells (PLC) from lung cancer patients grown as explant cultures, over a period of 12 weeks. PARP-1 protein was expressed in all the cell culture derived from bronchial epithelium explants. ${ }^{22}$ Recent data on PARP-1 agree on the meaning of this gene expression in tumors. Accordingly, the results of this study indicate that $P A R P-1$ gene may play a role in Pca. ${ }^{27}$ In conclusion, PARP-1 over-expression in prostate cancer tissues compared with normal prostate cells suggests a greater activity of PARP-1 in these tumors. In addition, PARP-1 proteins was expressed in a significantly greater number of cells in sample with a greater Gleason score. These findings lead to hypothesize that PARP-1 protein over-expression in PCa is an attempt to trigger apoptosis in this type of tumor. This conclusion is similar to what already reported in many other cancers. $^{14}$

\section{References}

1. Steinberg GD, Carter BS, Beaty TH, Childs B, Walsh PC. Family history and the risk of prostate cancer. Prostate 1990;17: 37-47.

2. Kucuk 0. Chemoprevention of prostate cancer. Cancer Metastasis Rev 2002;21: 111-24.

3. Jemal A, Siegel R, Ward E, Murray T, Xu J, Thun MJ. Cancer statistics CA. Cancer J Clin 2007;57:43-66.

4. Trojan L, Kiknavelidze K, Knoll T, Alken P, Michel MS. Prostate cancer therapy: standard management, new options and experimental approaches. Anticancer Res 2005;25: 551-61.

5. Walczak JR, and Carducci MA, Prostate cancer: a practical approach to current management of recurrent disease. Mayo. Clin Proc 2007; 82: 243-49.

6. Guseva NV, Taghiyev AF, Rokhlin OW, Cohen MB. Death receptor-induced cell death in prostate cancer. $\mathrm{J}$ Cell Biochem 2004;91:70-9.

7. Zornig M, Hueber A0, Baum W, Evan G. Apoptosis regulators and their role in tumorigenesis. Biochim Biophys Acta 2001;1551:F1-F37.

8. Hassa PO, Hottiger M0. The diverse biological roles of mammalian PARPs, a small but powerful family of poly-ADP-ribose polymerases. Front Biosci 2008;13:304682.

9. Hassa P0, Haenni SS, Elser M, Hottiger MO. Nuclear ADP-ribosylation reaction in mammalian cells: where are we today and where are we going? Microbiol Mol Biol Rev 2006;70:789-829.

10. Kim MY, Zhang T, Kraus WL. Poly(ADPribosyl)ation by PARP-1: 'PAR-laying' $\mathrm{NAD}+$ into a nuclear signal. Genes Dev 2005;19:951-67.

11. Burkle A. Poly(APD-ribosyl)ation, a DNA damage-driven protein modification and regulator of genomic instability. Cancer Lett 2001;163:1-5.

12. Schreiber V, Dantzer F, Ame JC, de Murcia G. Poly(ADP-ribose): novel functions for an old molecule. Nat Rev Mol Cell Biol 2006;7:517-28.

13. Ossovskaya V, Koo IC, Kaldjian EP, Alvares C, Sherman BM. Up-regulation of poly(ADP-ribose) polymerase-1 (PARP1) in triple-negative breast cancer and other primary human tumor types. Genes Cancer 2010;8:812-21.

14. Eustermann S, Videler H, Yang JC, Cole PT, Gruszka D. The DNA-binding domain of human PARP-1 interacts with DNA single-strand breaks as a monomer through its second zinc finger. J Mol Biol 2011; 4071:49-170.

15. Sulzyc-Bielicka V, Domagala P, Hybiak J, Majewicz-Broda A, Safranow K, Domagala W. Colorectal cancers differ in respect of PARP-1 protein expression. Pol J Pathol 2012;63:87-92.

16. Klauschen F, von Winterfeld M, Stenzinger A, Sinn BV, Budczies J, Kamphues C, et al. High nuclear poly-(ADP-ribose)-polymerase expression is prognostic of improbe survival in pancreatic cancer. Histopathology 2012;61:409-16.

17. Shimizu S, Nomura F, Tomonaga T, Sunaga M, Noda M, Ebara M, et al. Expression of poly(ADP-ribose) polymerase in human hepatocellular carcinoma and analysis of biopsy specimens obtained under sonographic guidance.
Oncol Rep 2004;12:821-25.

18. Csete B, Lengyel Z, Kádár Z, Battyáni Z. Poly(adenosine diphosphate-ribose) polymerase-1 expression in cutaneous malignant melanomas as a new molecular marker of aggressive tumor. Pathol Oncol Res 2009;15:47-53.

19. Galia A, Calogero AE, Condorelli R, Fraggetta F, La Corte A, Ridolfo F, et al. PARP-1 protein expression in glioblastoma multiforme. Eur J Histochem 2012;56:e9.

20. Ro YK, Lee S, Jeong CW, Hong SK, Byun SS, Lee SE. Biochemical recurrence in Gleason score 7 prostate cancer in korean men: significance of the primary Gleason grade. Korean J Urol 2012;12:826-9.

21. Epstein JI, Allsbrook WC Jr, Amin MB, Egevad LL, ISUP Grading Committee. The 2005 International Society of Urological Pathology (ISUP) Consensus Conference on Gleason Grading of Prostatic Carcinoma. Am J Surg Pathol 2005;1:22842.

22. Salemi M, Calogero AE, Zaccarello G, Castiglione R, Cosentino A, Campagna C, et al. Expression of SPANX proteins in normal prostatic tissue and in prostate cancer. Eur J Histochem 2010;54:e41.

23. Kannan S, Fang W, Song G, Mullighan CG, Hammitt R, McMurray J. Notch/HES1mediated PARP1 activation: a cell-type specific mechanism for tumor suppression. Blood 2011;117:2891-900.

24. Tentori L, Leonetti C, Scarsella M, D'Amati G, Vergati M. Systemic administration of GPI 15427, a novel poly(ADP-ribose) polymerase-1 inhibitor, increases the antitumor activity of temozolomide against intracranial melanoma, glioma, lymphoma. Clin Cancer Res 2003;9:5370-9.

25. Russo AL, Kwon HC, Burgan WE, Carter D, Beam $\mathrm{K}$, Weizheng $\mathrm{X}$. In vitro and in vivo radiosensitization of glioblastoma cells by the poly (ADP-ribose) polymerase inhibitor E7016. Clin Cancer Res 2009; 5:607-12

26. McEllin B, Camacho CV, Mukherjee B, Hahm B, Tomimatsu N. PTEN loss compromises homologous recombination repair in astrocytes: implications for glioblastoma therapy with temozolomide or poly(ADP-ribose) polymerase inhibitors. Cancer Res 2010;70:5457-64.

27. Ahmad M, Torky A, Glahn F, Scheubel RJ, Foth H. PARP-1 expression and activity in primary human lung cells. Arch Toxicol 2011;85:669-79. 